\title{
Alat Pencetak Tanggal Kadaluarsa pada Plastik Pack dengan Metode Hot Stamping
}

\author{
Eko Syamsuddin ${ }^{1}$ \\ Badan Pengkajian dan Penerapan Teknologi (BPPT) Jakarta \\ Email : ekosh2515@ hotmail.com \\ Makclin $^{2}$ \\ Program Studi Teknik Elektro Universitas Tarumanagara \\ Yohanes Calvinus ${ }^{2}$ \\ Program Studi Teknik Elektro Universitas Tarumanagara \\ Email : yohanesc@ft.untar.ac.id
}

\begin{abstract}
Food and beverage producers are required to put an expiration date on each production package in accordance with SNI. So far, small-scale entrepreneurs have affixed the expiration date by attaching stickers, installing the expiration mark in this way requires a relatively long time, so that the product ready for distribution is hampered in its distribution. To overcome this, we need a machine that can help small entrepreneurs to reduce the time in affirming the expiration date. This tool can print the expiration date automatically by the hot stamping method. This tool uses an AC motor to drive the rewinder and a DC motor to run the stamping head. Changing the date of printing is also easy, just use an L key to release and install characters. This tool is controlled by a microcontroller as a regulator of input, output, and printing distance settings with a choice of 10 modes. The conclusion that can be drawn from the design of an expiry date printing tool on a plastic pack with the hot stamping method is that the expiry date printing device on this plastic package can print an expiration date on plastic with a stamping head distance of $2.6 \mathrm{~cm}$ and the printing distance is determined by the input mode of the user assisted by eye-mark sensors in accordance with the plastic layout design. Starting from an average distance of $1.22 \mathrm{~cm}$ for Mode 1, up to $9.26 \mathrm{~cm}$ for Mode 10. Based on these conclusions, this tool has been tested to print well in a choice of 10 modes automatically.
\end{abstract}

Keyword: , automatically; expiry date; hot stamping; microcontroller; rewinder.

\begin{abstract}
ABSTRAK: Produsen makanan dan minuman diwajibkan mencantumkan tanggal kadaluarsa pada setiap kemasan produksinya sesuai dengan SNI. Pengusaha kecil selama ini membubuhi tanggal kadaluarsa dengan menempelkan stiker, pemasangan tanda kadaluwarsa dengan cara ini membutuhkan waktu yang relatif lama, sehingga produk siap edar terhambat dalam distribusinya. Untuk mengatasi hal tersebut, dibutuhkan mesin yang dapat membantu pengusaha kecil untuk mengurangi waktu dalam pembubuhan tanggal kadaluarsa. Alat ini dapat mencetak tanggal kadaluarsa secara otomatis dengan metode hot stamping. Alat ini menggunakan motor AC untuk menggerakkan rewinder dan motor DC untuk menjalankan stamping head. Penggantian tanggal pencetakan juga mudah, hanya menggunakan sebuah kunci L untuk melepas dan memasang karakter. Alat ini dikendalikan oleh mikrokontroler sebagai pengatur input, output, serta pengaturan jarak pencetakan dengan pilihan 10 mode. Kesimpulan yang dapat diambil dari perancangan alat pencetak tanggal kadaluarsa pada plastik pack dengan metode hot stamping adalah alat pencetak tanggal kadaluarsa pada kemasan plastik ini dapat mencetak tanggal kadaluarsa pada plastik dengan jarak stamping head 2,6 cm dan jarak pencetakan dideterminasikan dengan input mode dari pengguna yang dibantu oleh sensor eye-mark sesuai dengan layout design plastik. Mulai dari jarak rata-rata 1,22 cm untuk Mode 1, hingga 9,26 cm untuk Mode 10. Berdasarkan hasil kesimpulan tersebut alat ini telah teruji dapat mencetak dengan baik di pilihan 10 mode tersebut secara otomatis.
\end{abstract}

Kata Kunci: tanggal kadaluarsa; rewinder; otomatis; hot stamping; mikrokontroler.

\section{PENDAHULUAN}

Banyak sekali produk sehari-hari yang setelah diproduksi, perlu dikemas dalam plastik sehingga dapat dikonsumsi atau digunakan secara instan. Tidak hanya makanan instan, tetapi juga cairan atau bubuk untuk pembersih seperti sabun refill cair untuk mandi, cuci piring, pembersih lantai dan sebagainya, karena itu pemerintah Indonesia mengeluarkan ketentuan kelayakan bahwa setiap produk harus diberikan penandaan antara lain tanggal kadaluwarsa. Produsen makanan dan minuman diwajibkan mencantumkan tanggal kadaluarsa pada setiap kemasan produksinya sesuai dengan SNI. Pengusaha kecil selama ini membubuhi tanggal kadaluarsa dengan menempelkan stiker, pemasangan tanda kadaluwarsa dengan cara ini membutuhkan waktu yang relatif lama, sehingga produk siap edar terhambat dalam distribusinya

Selain itu dalam setiap kemasan juga mencantumkan tanda Standar Nasional Indonesia (SNI) yang dikeluarkan oleh Badan Standar Nasional Indonesia dan tanggal kadaluwarsa atas produk tersebut. Pemasangan tanggal kadaluwarsa tersebut ada yang menggunakan stiker dan ada yang

\footnotetext{
${ }^{1}$ Badan Pengkajian dan Penerapan Teknologi (BPPT) Jakarta

${ }^{2}$ Program Studi Teknik Elektro Universitas Tarumanagara
} 
menggunakan mesin. Kebutuhan mesin tersebut sangat diperlukan mengingat banyaknya kemasan produk yang harus diberikan penandaan. Untuk itu saat ini banyak sekali orang yang menjual mesin pencetak tanggal kadaluwarsa. Ada beberapa tipe mesin, diantaranya ada mesin inkjet printer, mesin hot ink roll, mesin laser printer, mesin punching sampai ke mesin stamping.Contoh mesin terssbut seperti pada Gambar 1.

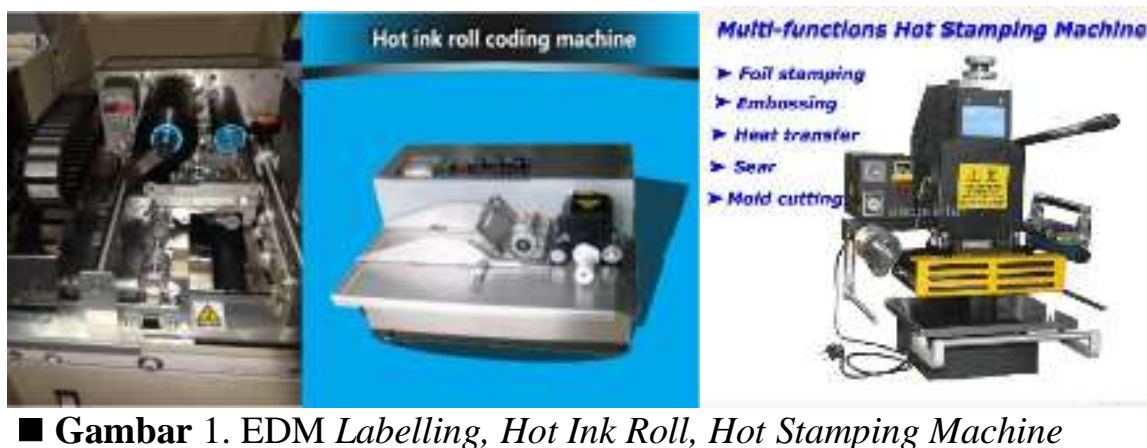

Beberapa jenis alat printing tersebut, mesin yang paling banyak dipakai adalah mesin inkjet printer, namun mesin tersebut tidak dapat digunakan oleh industri kecil karena harganya yang sangat tinggi. Oleh karena itu, untuk membantu perkembangan industri kecil atau home industry, perancangan mesin yang kecil dengan harga yang relatif rendah tetapi masih memenuhi standar SNI akan membantu banyak industri kecil. Salah satu caranya adalah dengan merancang stamping printer. Dengan alat ini, pencetakan tanggal kadaluwarsa ke atas kemasan plastik dari produk menjadi lebih mudah karena alat ini dilengkapi dengan sistem penggulung (rewinder) dan juga memiliki ketahanan yang baik terhadap gesekan karena tinta meresap ke dalam pori. Berdasarkan hal tersebut, penulis merancang alat pencetak tanggal kadaluwarsa yang menggunakan metode hot stamping agar dapat membantu industri kecil dalam pengadaan alat pencetak yang lebih murah harganya.

\section{METODE PERANCANGAN}

Perancangan alat pencetakan tanggal kadaluwarsa pada plastik pack dengan metode hot print stamping dimulai dengan survei ke PT. Dynamic Synergy International dan PT. Gunawan Elektrindo, dengan hasil seperti pada Tabel 1. Berdasarkan hasil analisis dan diskusi dengan beberapa pengusaha kecil, maka perancangan alat ini dikhususkan untuk mencetak tanggal kadaluwarsa pada bungkusan produk plastik dengan sistem hot stamping, dimana tinta pada ribbon tape akan meleleh jika stamping head mengenai ribbon pada suhu $100^{\circ} \mathrm{C}$. Tipe plastik yang dapat dicetak dengan printer ini adalah plastik polipropilen (PP) karena plastik ini dapat menahan panas sampai $140^{\circ} \mathrm{C}$. Cara kerja alat ini adalah saat dinyalakan, catridge heater akan langsung memanaskan karakter pada stamping head sampai suhu $100^{\circ} \mathrm{C}$. Suhu panas diatur oleh thermo control dan suhu dideteksi dengan thermo couple. Karakter yang terdapat di stamping head bersusunan sesuai urutan tanggal/bulan/tahun (DDMMMYY).

Tabel 1. Hasil Surve Mesin Pencetakan

\begin{tabular}{|c|l|l|}
\hline No. & Produk PT. Dynamic Synergy & \multicolumn{1}{c|}{ Produk PT. Gunawan Elektrindo } \\
\hline 1. & Pencetakan menggunakan panas & Pencetakan tidak menggunakan panas. \\
\hline 2. & Tipe tinta adalah ribbon tape ink. & Tipe tinta adalah solvent base ink. \\
\hline 3. & Gambar dicetak secara digital. & Gambar dicetak harus dengan plat cetakan. \\
\hline 4. & $\begin{array}{l}\text { Kualitas pencetakkan } \\
\text { berubah seiring berubahnya }\end{array}$ & $\begin{array}{l}\text { Kualitas pencetakkan sama, namun ada } \\
\text { kecepatan maksimum. }\end{array}$ \\
\hline 5. & Ribbon tape tidak menimbulkan & Tinta menguap dan menimbulkan polusi \\
\hline 6. & $\begin{array}{l}\text { Alat dapat beroperasi secara otomatis } \\
\text { dengan }\end{array}$ & Mesin beroperasi secara manual \\
\hline
\end{tabular}

Alat ini mulai bekerja dengan cara pengguna pertama harus memilih mode dari 10 mode yang terdapat pada alat ini. Setiap mode memiliki pilihan jarak yang berbeda, semakin tinggi mode yang dipilih maka semakin jauh jarak pencetakkan dari sensornya. Setelah memilih mode, pengguna harus menekan start untuk memulai menjalankan rewinder. Awalnya rewinder akan berjalan dengan tenaga motor AC sampai sensor eye-mark menemukan sensor batas pada plastik, lalu mikrokontroler akan menjalankan timer. Timer berjalan sesuai dengan mode yang diatur dari program. Setelah timer habis 
menghitung, maka rewinder akan berhenti.

Setelah rewinder berhenti, mikrokontroler memerintahkan stamping head untuk mencetak. Stamping head mencetak dengan mengikuti gerakan motor DC. Motor DC bergerak berlawanan arah jarum jam. Awalnya sumbu stamping head yang terhubung ke motor DC berada pada jam angka 12 yang artinya stamping head sedang terletak pada posisi awal. Selanjutnya sumbu akan bergerak ke arah jam angka 9 menuju ke angka 6 di mana pada saat sampai ke posisi angka 6 proses stamping terjadi. Setelah itu sumbu berputar kembali menuju arah jam angka 12 melalui angka 3 di mana sumbu selain mengangkat stamping head, juga akan mengangkat dua buah tuas di mana satu tuas untuk menekan limit switch dan satu lagi secara mekanis akan menggulung kembali ribbon tape. Ribbon tape digulung kembali karena bagian yang sudah digunakan untuk mencetak tidak dapat digunakan lagi. Limit switch akan tertekan saat sumbu mencapai angka 12 dan mengirimkan sinyal ke mikrokontroler untuk menjalankan kembali rewinder untuk mencetak selanjutnya. Gambar 2 menunjukkan stamping printer

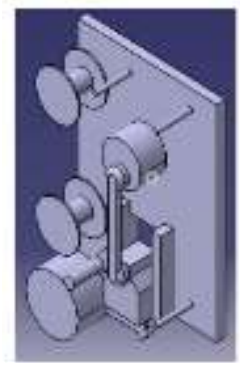

Gambar 2. Stamping Printer

Pada alat ini terdapat tiga buah tombol dan sebuah LCD sebagai interface dari alat ini. Tiga buah tombol pada alat ini terdiri dari satu tombol pemilih mode, satu tombol untuk start (menjalankan alat) dan satu tombol untuk stop (menghentikan alat). LCD awalnya saat dinyalakan akan menampilkan introduksi berupa pesan "Welcome to Stamping Machine", lalu selanjutnya langsung menampilkan mode yang dipilih. Setelah tombol start ditekan maka LCD akan menampilkan pesan "rewinder running". Saat tombol stop ditekan, tampilan akan kembali ke tampilan pilihan mode.

Gambar rancangan dapat dilihat pada Gambar 3. Adapun spesifikasi teknis dari alat yang dirancang dapat dilihat pada

Tabel 2. Diagram blok diawali dengan modul pemeroses yang memberikan perintah kepada inverter untuk menggerakan motor AC. Motor AC akan bergerak hingga sensor eye- mark mendeteksi batas. Setelah batas terdeteksi maka pemeroses akan menggerakan motor DC untuk melakukan penstempelan. Setelah itu motor DC akan dihentikan dengan limit switch dan menjalankan kembali motor AC.

Tabel 2. Spesifikasi Teknis dari Alat yang Dirancang

\begin{tabular}{|c|c|c|}
\hline \multicolumn{3}{|c|}{ Spesifikasi Teknis } \\
\hline 1 & Catu daya & $220 V_{A C}$ \\
\hline 2 & Dimensi (Panjang x Lebar x Tinggi). & $80 \mathrm{~cm} \mathrm{X} \mathrm{50cm} \mathrm{X} \mathrm{60cm}$ \\
\hline 3 & Pemroses & Mikrokontroler ATmega16 \\
\hline 4 & Bahan Karakter & Kuningan. \\
\hline 5 & Ukuran karakter & $2 \mathrm{~mm}-3 \mathrm{~mm}$. \\
\hline 6 & Sensor & Eye-Mark \\
\hline 7 & LCD display & $2 \times 16$ Karakter \\
\hline 8 & Kecepatan & 20 stamp / menit \\
\hline 9 & Tinta & Ribbon Tape \\
\hline 10 & Temperature Cetak & $100^{\circ} \mathrm{C}$ \\
\hline 11 & Pemanas & catridge heater \\
\hline 12 & Motor DC & $12 \mathrm{~V}_{\mathrm{DC}}-2 \mathrm{~A}$ \\
\hline 13 & Motor AC & 3 fasa \\
\hline
\end{tabular}




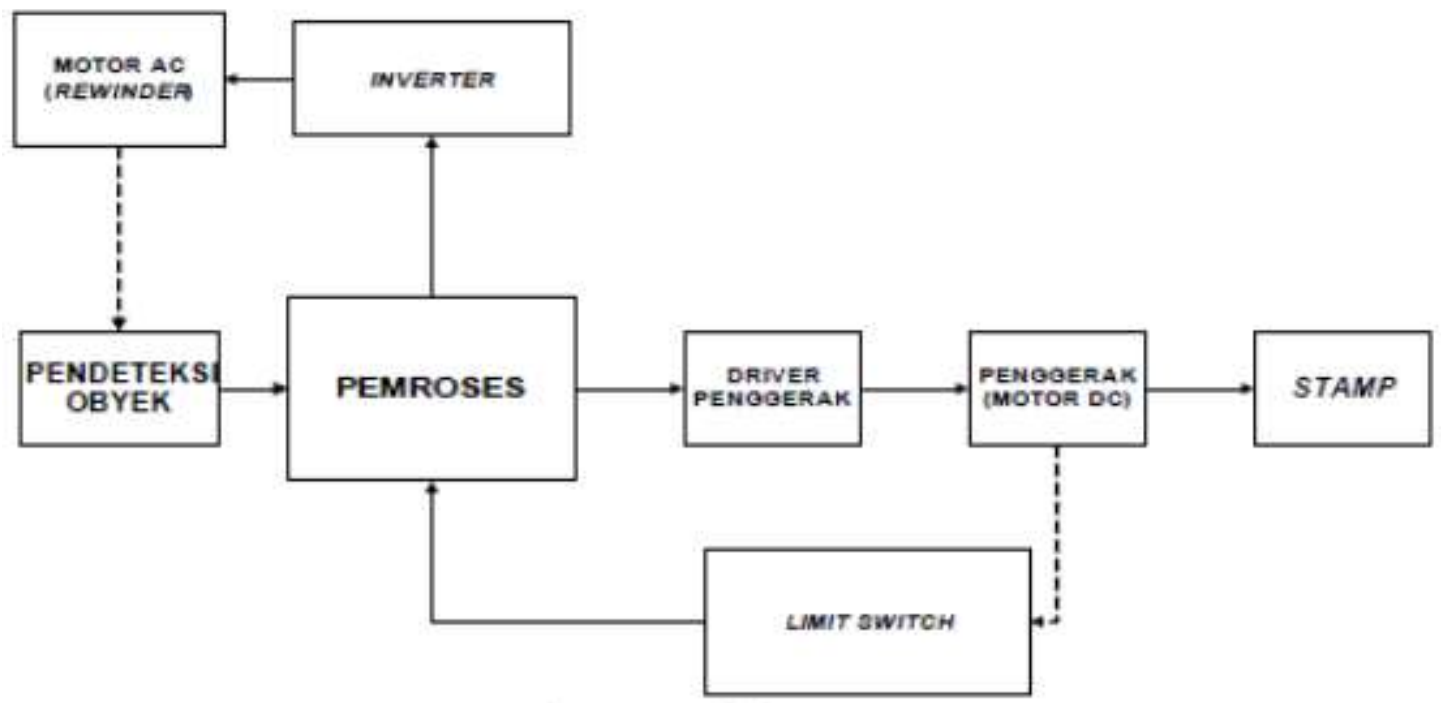

- Gambar 3 Digaram Blok Rancangan

Mekanik pencetak adalah dengan cara mencetak dengan tenaga sebuah motor DC yang berputar berlawanan arah jarum jam. Dengan perputaran tersebut, stamping head yang terhubung ke ujung sumbu motor DC dapat diangkat naik dan turun seperti sebuah piston. Stamping head dengan ujung motor DC disambungkan dengan menggunakan sebuah roll connector. Gambar dari susunan tersebut dapat dilihat pada Gambar 4. Selain itu, Stamping head yang bergerak selain bergerak untuk menstampel, juga bekerja sebagai penggulung kembali ribbon tape yang sudah terpakai untuk stampel dengan bantuan dari one way bearing.

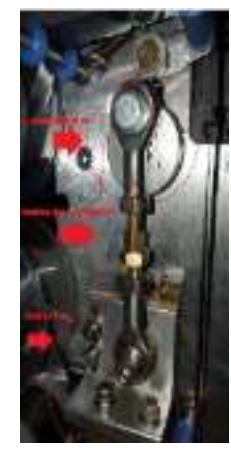

- Gambar 4. Hubungan Sumbu Motor DC dengan Stamping Head

Pancangan alat pencetak tanggal kadaluwarsa beserta dengan rewinder semua diatur dengan menggunakan mikrokontroler. Mikrokontroler yang digunakan dalam pengaturan jalannya alat ini adalah mikrokontroler Atmel ATmega16. Dengan menggunakan rangkaian minimum sistem, IC mikrokontroler ATmega16 sudah dapat mengoperasikan sesuai dengan kerja dari alat pencetak ini. Berikut Gambar dari rangkaian minimum sistem ATmega16 dapat dilihat pada Gambar 5. Dari rangkaian minimum sistem ini, selain IC ATmega16, juga dilengkapi dengan Kristal sebesar $8 \mathrm{MHz}$. Kristal ini berfungsi sebagai clock pada rangkaian mikrokontroler ATmega16. Selain dari komponen tersebut, rangkaian minimum sistem ini dilengkapi dengan sebuah led sebagai indikator menyala dan sebuah push button sebagai tombol reset untuk mikrokontroler. 


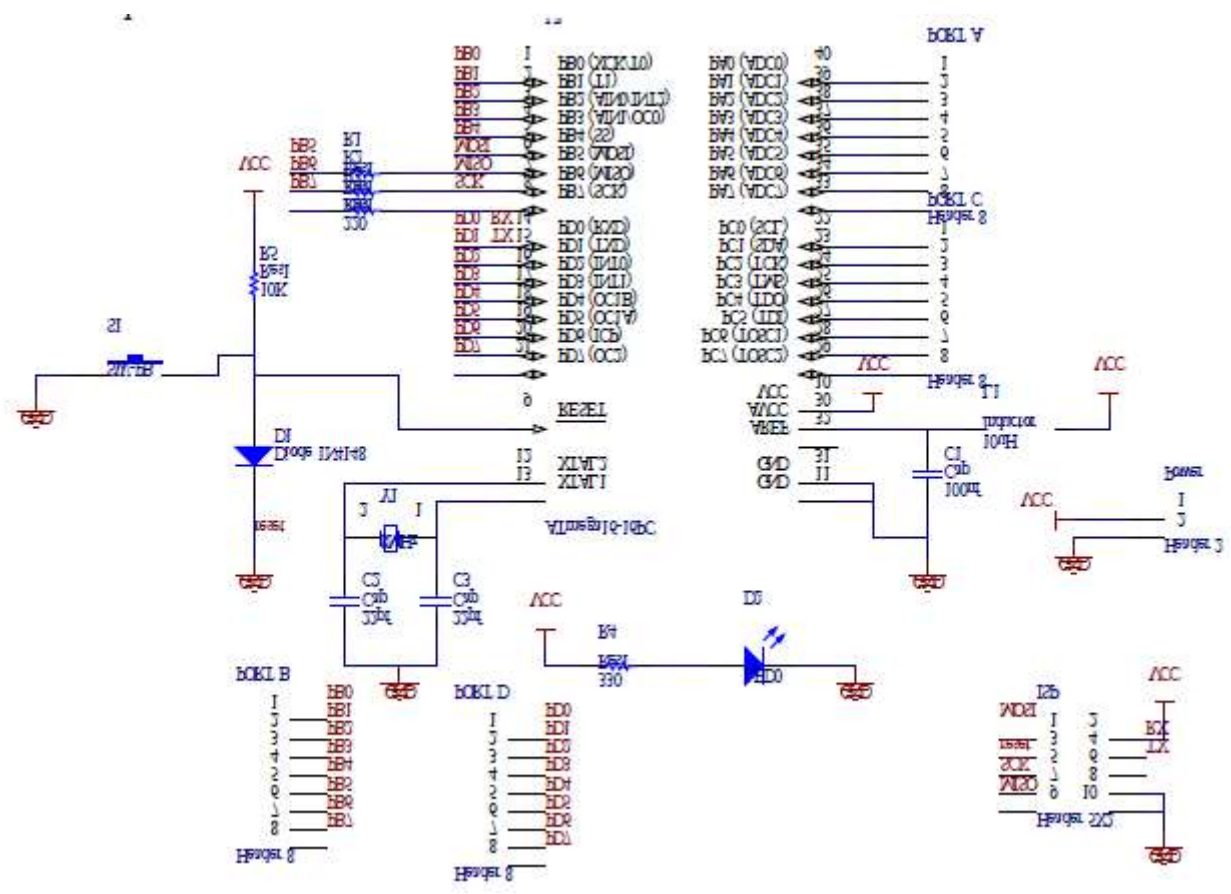

- Gambar 5. Rangkaian minimum system ATMega16

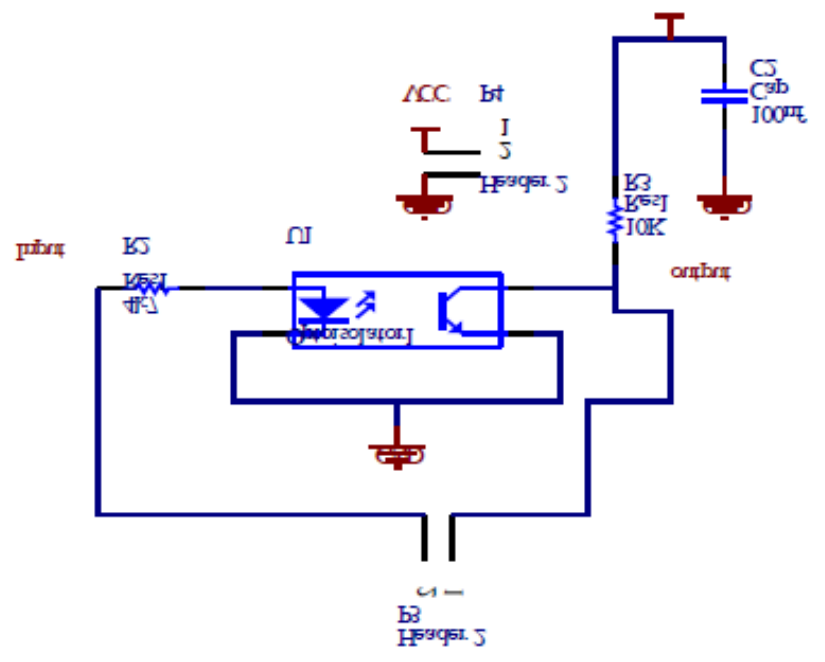

- Gambar 6. Rangkaian

Realisasi rancangan modul optocoupler menggunakan IC optocoupler sebagai komponen utama.Rancangan modul ini digunakan untuk mengubah sinyal yang dihasilkan oleh sensor eye-mark, yang mana output dari sensor tersebut menghasilkan tegangan $12 \mathrm{~V}_{\mathrm{DC}}$, kemudian diubah menjadi tegangan $5 \mathrm{~V}_{\mathrm{DC}}$ agar dapat dibaca oleh mikrokontroler sebagai logika high dan low. Rangkaian optocoupler dapat dilihat pada Gambar 6. Berdasarkan rangkaian optocoupler ini, output dari sensor sebelum masuk ke optocoupler dipasang resistor $4,7 \mathrm{k} \Omega$, yang berfungsi sebagai tahanan agar arus yang masuk ke bagian led optocoupler tidak terlalu besar. Output dari optocoupler dipasang resistor sebagai rangkaian pull up agar dapat menjadi sinyal high dan low pada mikrokontroler.

Realisasi rancangan modul relay sebagai komponen utamanya. Modul relay pada perancangan ini berfungsi sebagai automatic switch. Automatic switch yang dimaksud pada perancangan ini adalah untuk mengontrol inverter agar dapat menjalankan dan menghentikan motor rewinder sesuai dengan logika yang diberikan oleh mikrokontroler. Gambar rangkaian relay dapat dilihat pada Gambar 7. 


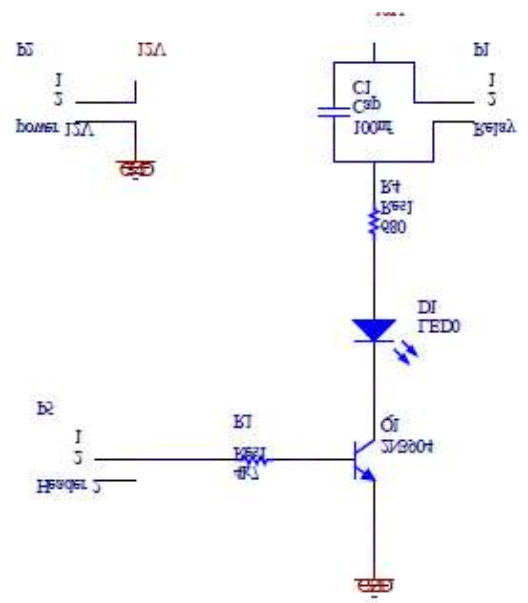

- Gambar 7. Rangkaian Relay

Realisasi rancangan modul Liquid Crystal Display (LCD) berfungsi sebagai tampilan untuk memudahkan pengguna dalam pengoperasian alat yang dirancang. Tampilan dari LCD berupa pilihan untuk memilih jarak stampel yang akan diinginkan oleh pengguna. Jarak yang dipilih dikonversi menjadi beberapa mode. Rangkaian LCD dapat dilihat pada Gambar 8.

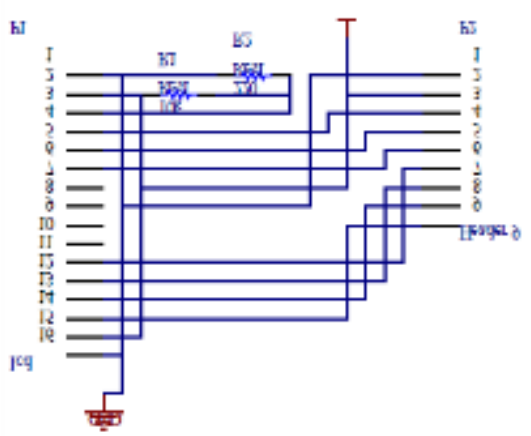

Mekanik Rewinder

- Gambar 8. Rangkaian Liquid Crystal Display

Realisasi rancangan mekanik rewinder diawali dari mempelajari cara penggulungan sebuah material dengan rapi. Dalam pembelajaran ini, kunci dari penggulungan adalah kesejajaran. Jika gulungan tidak sejajar, maka akan terjadi pergeseran pada material yang digulung, maka dari ini, dipilihlah materi dasar pembuatan yang kuat dan tidak mudah berubah bentuk. Untuk sumbu mounting roll plastik digunakan bahan stainless steel. Contoh mounting roll seperti pada Gambar 9. Setelah itu material body yang kuat dan mudah untuk dipotong, digunakan aluminium sebagai body dan sebagai penahan AS untuk mounting roll plastik. Ketebalan dari body digunakan 2 ukuran dimana dibentuk seperti Gambar 3.27 dimana plat aluminium sebelah kiri dan kanan berketebalan $15 \mathrm{~mm}$ dan plat yang ditengah berketebalan $10 \mathrm{~mm}$. plat ditengah lebih tipis karena dengan pemasangan tanam kedalam, beban pada plat tengah dibagi ke plat kiri dan kanan. 


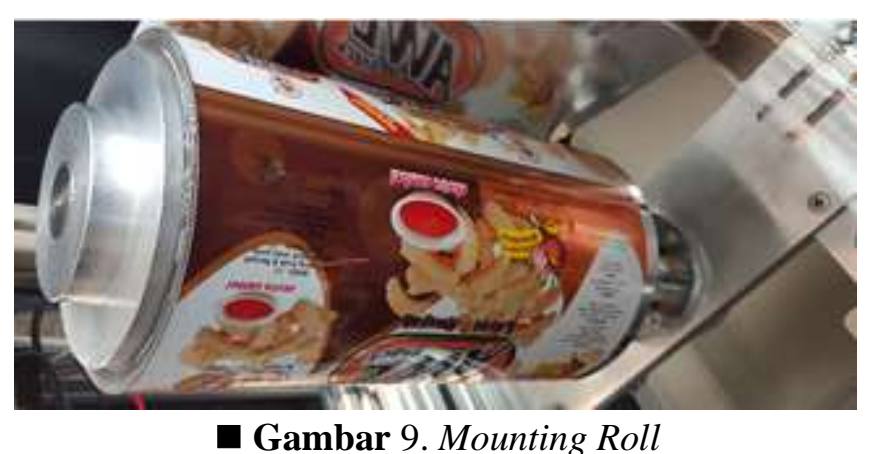

Beban plat kiri dan kanan menahan beban dari perlengkapan mekanikal disisi kiri, plat ini menahansebuah roll alumunium yang berfungsi sebagai jalur pelastik sumbu mounting roll dilengkapi dengan dudukan roll yang berisi 2 buah bearing supaya roll dapat berputar tanpa mengalami gesekan. Selain itu plat sisi kiri juga memiliki roll dibagian belakang yang berbentuk seperti pulley yang ditahan dengan menggunakan sebuah tali kulit n Pulley tersebut berfungsi sebagai tensioner supaya plastik roll selalu tegang saat dicetak. Tensioner dapat dilihat pada Gambar 10. Di sisi kanan terdapat beban terberat dari alat ini, yaitu sebuah motor AC dengan gearbox-nya. Dan hampir mirip dengan sisi kiri, disisi kanan juga dilengkapi sebuah roll aluminium sebagai jalur jalannya roll plastik dan terdapat sebuah dudukan sumbu AS stainless steel. Perbedaan sisi kanan dengan kiri adalah disisi kiri AS stainless dihubungkan ke pulley, di sisi kanan, AS dihubungkan langsung kedalam gearbox, dimana di dalam gearbox harus dibuatkan sebuah spi sebagai kunci untuk memutar AS stainless steel.

Selanjutnya bagian kaki dari perancangan ini. Bagian kaki dibuah seperti sebuah meja dengan 4 tapak kaki karet. Pembuatan kaki ini menggunakan bahan batang aluminium profile. Aluminium profile ini sedang menjadi trend pada masa kini karena perakitan mudah dan tidak harus menggunakan mesin las untuk menyambungkan dari batang ke batang. Dari aluminium profile ini dipasangkan dengan menggunakan beberapa baut L, connector siku dan beberapa sliding nut. Dari sisi kesejajaran, dibuatlah sisi kiri dengan kanan serta AS stainless steel dan dudukan sumbu roll secara simetris dan identikal. Dengan memiliki sumbu yang identikal, maka kesejajaran akan lebih mudah dicapai. Roll aluminium sebagai jalur juga dipilih yang identikal dan sejenis.

Rewinder yang terdapat di pasaran ada 2 macam, back and forth rewinder dan One way rewinder. Rewinder yang dirancang adalah one way pulling rewinder. One way artinya hanya satu arah, maka rewinder ini hanya bisa berputar maju dan tidak bisa mundur. Dengan sistem pulling, rewinder ini hanya bergerak satu arah dan menggulung dengan cara menarik. Di sisi kiri roll bersifat loose atau bisa diputar kiri kanan tanpa beban, sedangkan di sisi kanan, roll plastik dikunci ke AS dan diputar oleh motor AC sehingga bersifat menarik.

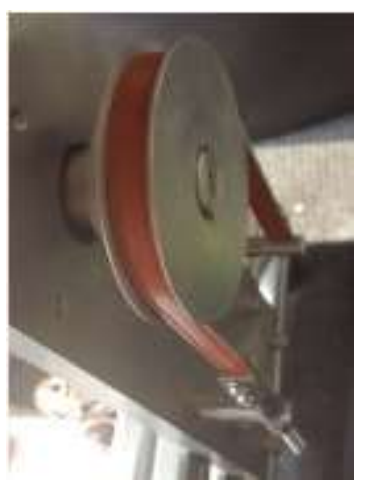

Gambar 10. Tensioner

Motor driver yang digunakan dalam perancangan ini adalah motor driver bermerk ST dengan tipe VNH2SP30. Motor driver ini memiliki keluaran arus maksimum 30 Ampere. Arus yang dikeluarkan cukup untuk menjalankan motor DC. Dengan menggunakan motor driver ini, motor DC dapat diatur kecepatan putarannya dengan mikrokontroler. Selain kecepatan, arah putaran dari motor DC juga dapat diatur. Gambar fisik dari IC motor driver dapat dilihat pada Gambar 11. 


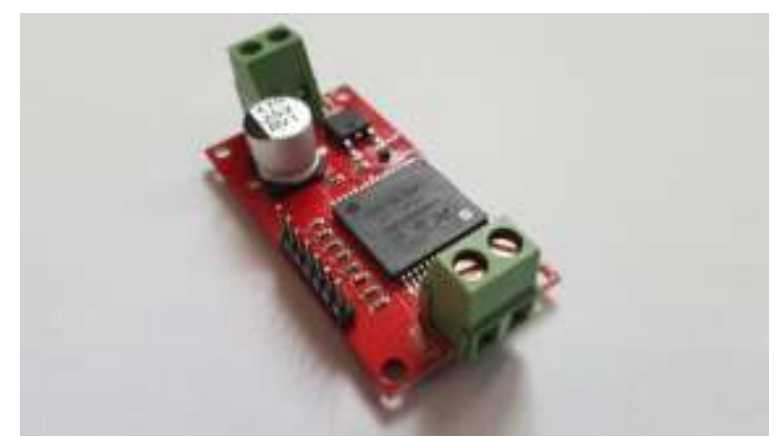

— Gambar 11. IC motor driver VNH2SP30

Eye-mark sensor mendeteksi warna kontras dari obyek. Sensor eye-mark yang digunakan adalah sensor bermerk Kontec dengan Seri KH-C2B. sensor ini bersifat active low, dimana saat mendeteksi batasan pada ujung bungkusan sinyal yang dikirim akan low dan saat tidak dikirim akan high. Sensor ini memberikan sinyal input sebesar $12 \mathrm{~V}_{\mathrm{DC}}$ sehingga harus n optocoupler supaya dapat berkomunikasi dengan mikrokontroler. Gambar dari sensor mbar 12.

Inverter adalah sebuah alat untuk mengendalikan motor AC 3 fasa. Gambar fisik dari inverter dapat dilihat pada Gambar 13. Inverter yang digunakan adalah inverter juga bermerk TPG dengan tipe CA202A. Inverter ini dapat digunakan untuk mengatur kecepatan dari motor AC 3 fasa dengan kecepatan maksimum $60 \mathrm{~Hz}$. Inverter ini memiliki beberapa port yang memiliki fungsinya sendiri. Berikut port yang terdapat pada inverter:

1. Grounding $=$ ground

2. $\mathrm{L} 1, \mathrm{~L} 2=$ Power Source

3. $\mathrm{U}, \mathrm{V}, \mathrm{W}=$ koneksi ke motor 3 fasa.

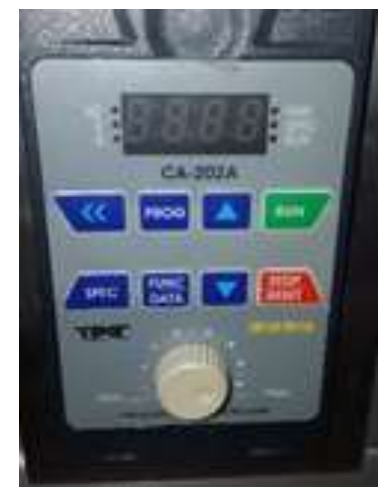

- Gambar 13. Inverte

Motor AC yang digunakan adalah motor AC 3 fasa yang bermerk TPG tipe MV-400100S dengan spesifikasi sebagai berikut:

1. Power $=100 \mathrm{Watt}$

2. Poles $=4$

3. Tegangan $=220 / 380 \mathrm{~V}$

4. Arus $=0,85 / 0,5 \mathrm{~A}$

5. Frekuensi $=50 / 60 \mathrm{~Hz}$

6. $\mathrm{RPM}=1450 / 1720$

7. Berstandar IP 54 ( tahan terhadap debu dan tahan terhadap cipratan air)

Motor ini juga sudah dilengkapi dengan gearbox dengan perbandingan ratio 1:10. Dengan adanya gearbox, torsi dari motor AC menjadi lebih tinggi walaupun kecepatan dari motor berkurang. Penggunaan motor AC menjadi lebih mudah karena gearbox menyediakan sebuah lubang untuk dimasukkan as dari benda yang akan diputar dan dapat dikunci di dalamnya. Gambar fisik dari motor AC ini dapat dilihat pada Gambar 14 


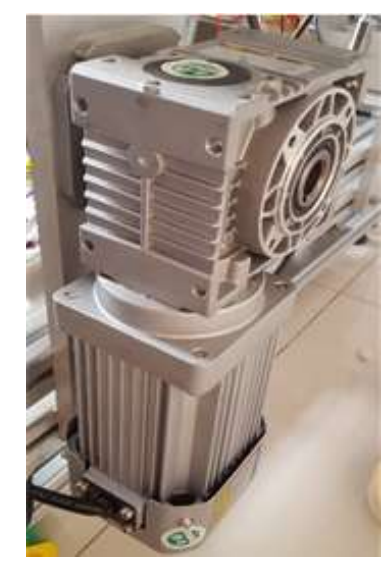

- Gambar 14. Motor AC

Thermo control adalah sebuah alat untuk mengatur panas dari cartridge heater. Thermo control yang digunakan adalah thermo control bermerk Keyang dengan tipe XMGT-8000. Thermo control ini memiliki 8 port input. Berikut input port dari Thermo control XMGT-8000:

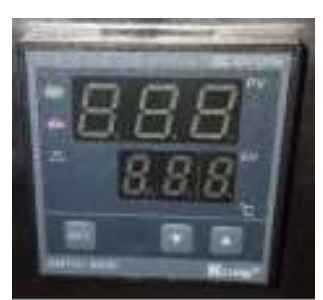

1. Grounding

- Gambar 15. Thermo Control

2. $220 \mathrm{~V}_{\mathrm{AC}}$

3. $220 \mathrm{~V}_{\mathrm{AC}}$

4. Output Positif

5. Output Negatif

6. Alarm

7. Alarm

8. Input Sinyal thermo couple

9. Ground untuk thermo couple

10. Vec untuk thermo couple

Dari port tersebut, port yang digunakan adalah port nomor 1 untuk Grounding, port 2 dan 3 untuk power, port 4 dan 5 untuk output ke cartridge heater, port 8,9 dan 10 untuk thermo couple. Port 6 dan 7 tidak digunakan karena tidak menggunakan alarm untuk indikator yang biasa bisa berupa buzzer. Thermo control ini memiliki range control suhu dari $0^{\circ} \mathrm{C}$ sampai dengan $300^{\circ} \mathrm{C}$. Gambar dari thermo control dapat dilihat pada Gambar 15.

Cartridge heater yang digunakan adalah cartridge heater berbentuk silinder dengan ukuran diameter $1 / 2$ " dan panjang 3,5 cm. Daya dari cartridge heater adalah 60 watt dan tegangan $220 \mathrm{~V}_{\mathrm{Ac}}$. Cartridge heater ini sudah cukup untuk memanaskan stamping head karena suhu maksimum dari cartridge heater ini sudah dapat mencapai panas setinggi $140_{0} \mathrm{C}$. Gambar fisik dari cartridge heater dapat dilihat pada Gambar 16

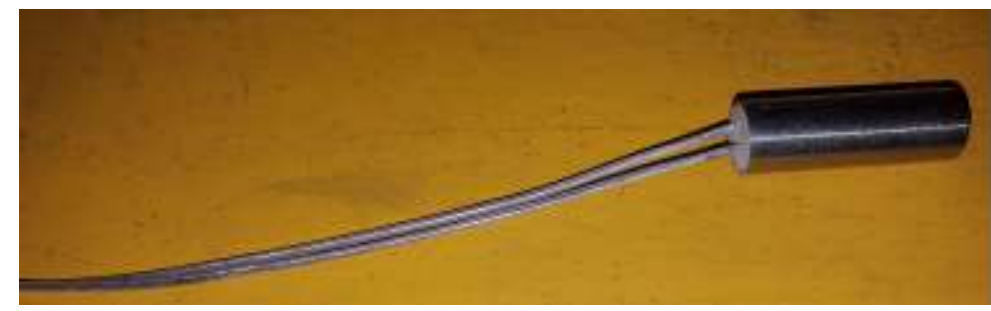

- Gambar 16. Cartridge Heater 
Thermo couple yang digunakan adalah thermo couple yang memiliki kemampuan mengukur suhu dengan range $0_{0} \mathrm{C}$ sampai dengan $300_{0} \mathrm{C}$. dengan ukurannya yang kecil dan jarak cangkupan suhu sebesar ini sudah cukup untuk mengukur suhu dari stamping head. Gambar fisik dari thermo couple dapat dilihat pada Gambar 17.

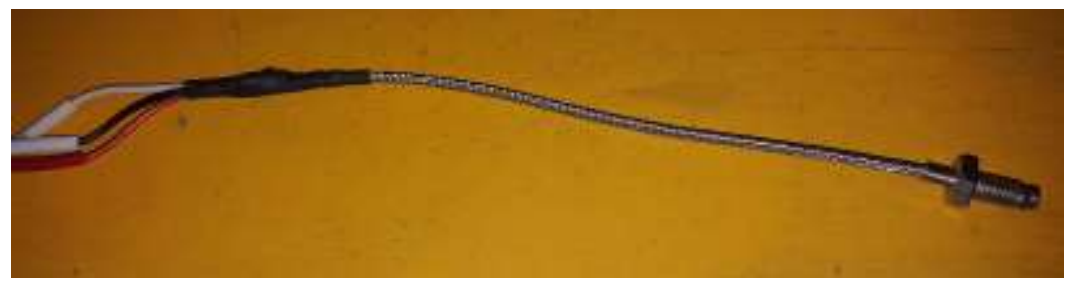

- Gambar 17. Thermo Couple

Stamping head ini terbuat dari kuningan yang dipasangkan dengan karakter kecil yang berukuran $3 \mathrm{~mm}$. Stamping head tipe ini dipakai karena karakteristik dari stamping head ini yang tahan terhadap panas karena terbuat dari kuningan dan ketebalan dari stamping head tersebut sehingga memungkinkan untuk dipasangnya cartridge heater dan thermo couple ke dalam stamping head tersebut. Bentuk fisik dari Character based Stamping head dapat dilihat pada Gambar 18

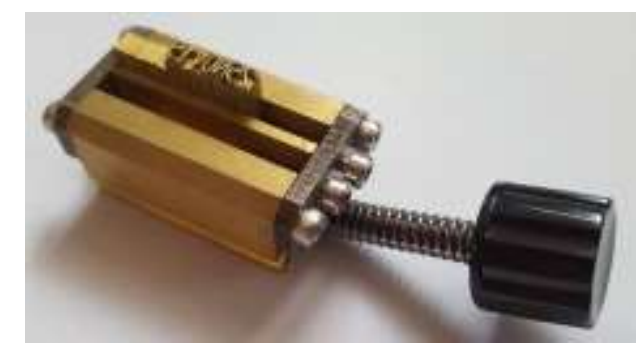

- Gambar 18. Character Based Stamping Head

Diagram Alir Rancangan Sstem.

Realisasi rancangan sistem adalah penggabungan semua modul baik mekanik dan elektronik menjadi sebuah alat yang bekerja sesuai dengan fungsinya. Penggabungan semua modul dengan modul mikrokontroler. Saat power dinyalakan, LCD akan menampilkan pesan introduksi berupa "welcome to Stamping Printer", lalu akan menunjukan Mode 0. Dibawah LCD memiliki 3 tombol sebagai input. Tombol pertama input mode dimana mode terdapat 1 sampai dengan 10. Tombol kedua adalah Start untuk menjalankan alat san tombol ketiga adalah Stop untuk menghentikan alat. Setelah pengguna memilih mode, tekan start untuk menjalankan sistem. Awalnya rewinder akan bergerak menggulung roll plastik sampai sensor eye-mark mendeteksi adanya tanda pada ujung plastik. Setelah mendeteksi tanda, rewinder akan berhenti dengan jarak sesuai dengan mode yang dimasukkan, lalu stamping head akan menstempel. Stempel akan berhenti setelah berputar 1 putaran dengan menggunakan limit switch sebagai penghenti. Setelah itu, rewinder akan berputar ulang dari awal. Flowchart cara kerja alat dapat dilihat pada Gambar 19. 


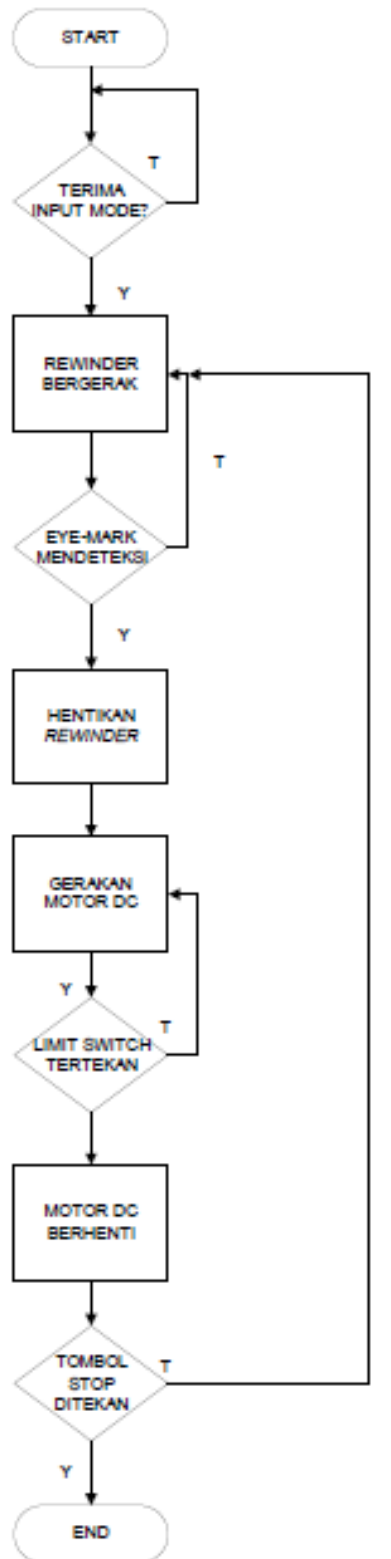

- Gambar 19. Diagram Alir Keseluruhan

\section{HASIL PENGUJIAN DAN ANALISIS}

Hasil Pengujian dan Analisis Jarak Stamping Head

Pengujian dan analisis stamping head bertujuan untuk mengurangi faktor kesalahan pencetakan seperti kerusakan pada karakter atau kerusakan pada plastik yang dicetak. Kerusakan ini disebabkan karena kesalahan penyesuaian jarak stamping head dengan sumbu motor stamping. Jika terlalu jauh maka stamping head akan menabrak bantal penahan terlalu keras mengakibatkan kerusakan pada plastik roll dan juga pada karakter. Hasil pengujian dapat dilihat pada Tabel 3. 
Tabel 3. Pengujian Jarak Stamping Head

\begin{tabular}{|c|c|c|c|}
\hline \multicolumn{4}{|c|}{ Jarak Pencetakan } \\
\hline $\begin{array}{c}\text { Jarak } \\
(\mathbf{c m})\end{array}$ & $\begin{array}{l}\text { Tercetak } \\
\text { (Ya/Tidak) }\end{array}$ & Kejelasan & Catatan \\
\hline 2.0 & Tid & & - \\
\hline 2.2 & Tid & & - \\
\hline 2.4 & Ya & Tidak Jelas & - \\
\hline 2.6 & Ya & Jelas & Jelas \\
\hline 2.8 & Ya & Jelas & $\begin{array}{c}\text { Jelas Tapi Pelastik Rusak Mengganggu } \\
\text { Putaran }\end{array}$ \\
\hline 3.0 & $\mathrm{Ya}$ & Jelas & Motor \\
\hline
\end{tabular}

Sesuai Tabel 3 di atas dapat dilihat bahwa jika kelebihan jarak maka akan mengakibatkan kerusakan pada head dan juga mengganggu jalannya motor stamping Hasil kejelasan pencetakan tanggal kadaluarsa pada Gambar 20. Sedangkan hasil realisasi dari perancangan alat dapat dilihat pada Gambar 21.
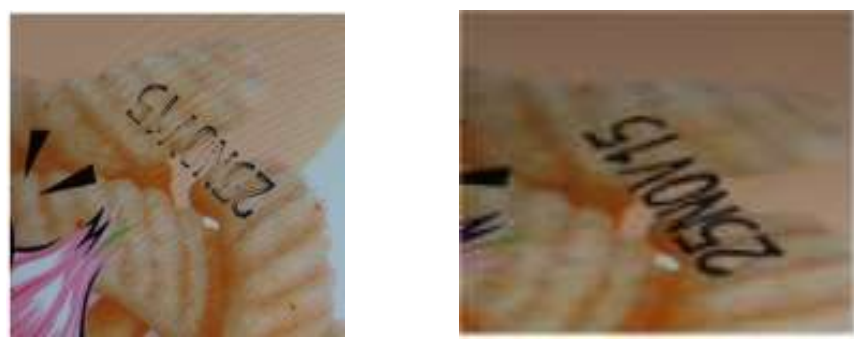

- Gambar 20. Hasil Pencetakan Kadaluarsa Kurang Jelas dan Jelas

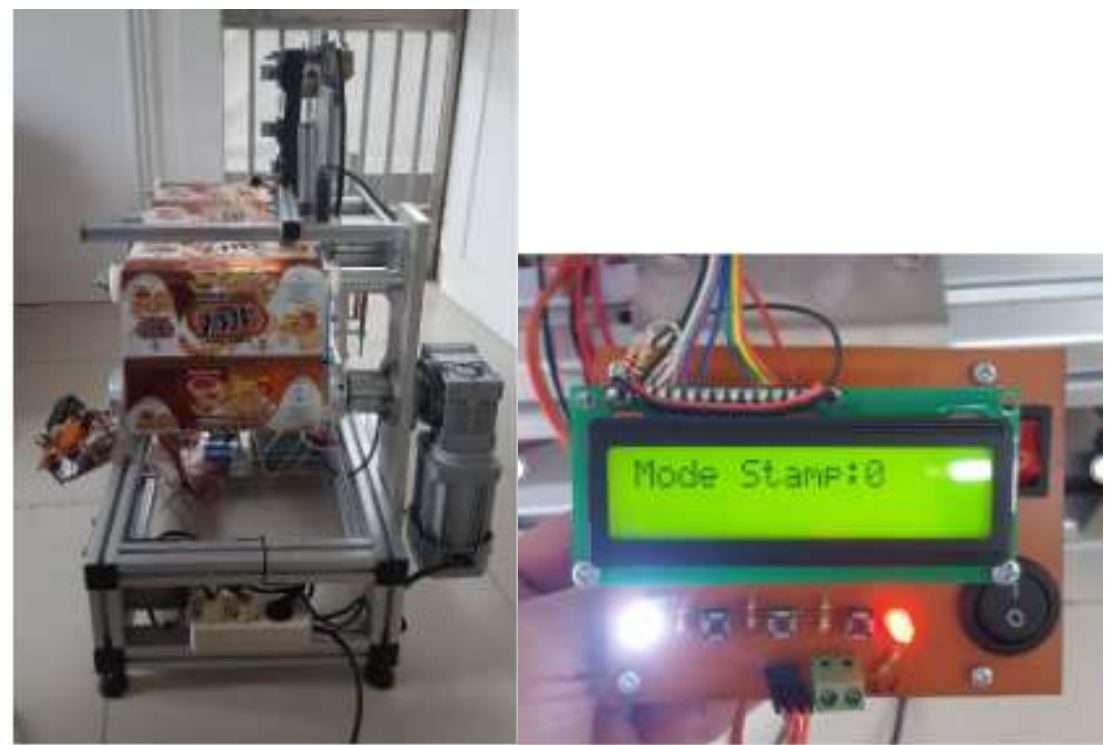




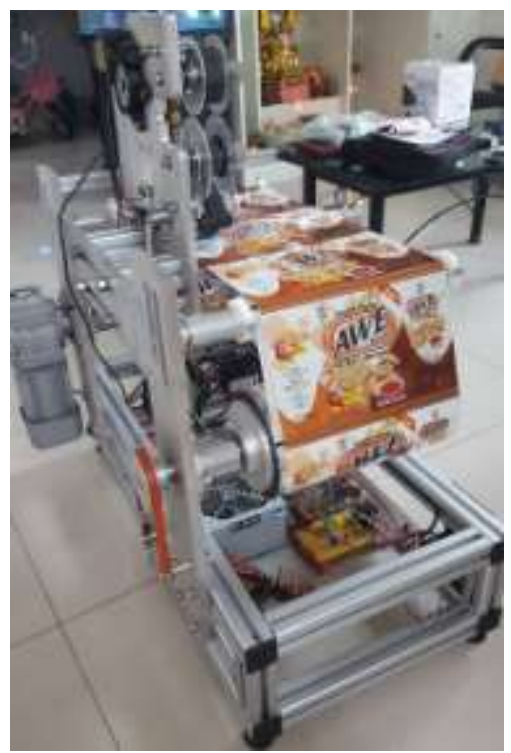

- Gambar 21. Hasil Realisasi Perancangan Alat

Pengujian dan analisis sistem untuk menguji penggabungan sistem dapat bekerja sesuai dengan perintah yang datang dari setiap modul dengan program dalam modul mikrokontroler. Sistem dikatakan berhasil bila pencetakan sesuai dengan mode yang dimasukkan. Jarak pencetakan ditentukan dari mode yang dipilih. Dalam pengujian ini, dilakukan 5 kali pengujian dalam setiap mode untuk mengetahui berapa jarak setiap mode dan bagaimana hasil pencetakan setiap modenya. Pengujian menggunakan pengaturan optimal sesuai dengan pengujian permodul sebelumnya seperti jarak stamping head $2,6 \mathrm{~cm}$ dan dengan suhu set $240{ }^{\circ} \mathrm{C}$ (suhu pada karakter

$136{ }^{\circ} \mathrm{C}$ ). Tabel 4 merupakan hasil pengujian yang dilakukan per mode. Ssuai hasil pengujian, dapat dilihat bahwa setiap mode memiliki perbedaan jarak. Dengan perbedaan jarak tersebut, maka alat dapat mencetak dibagian tertentu dengan pengaturan mode tersebut, sesuai dengan layout design.

Tabel 4. Hasil Pengujian Keseluruhan Sistem

\begin{tabular}{|c|c|c|c|c|c|c|}
\hline & \multicolumn{7}{|c|}{ Percobaan (cm) } \\
\hline Mod e & $\mathbf{1}$ & $\mathbf{2}$ & $\mathbf{3}$ & $\mathbf{4}$ & $\mathbf{5}$ & Rata-rata \\
\hline $\mathbf{1}$ & 1 & 1.5 & 1.1 & 1.5 & 1 & 1 \\
\hline $\mathbf{2}$ & 2.2 & 2.5 & 2.3 & 2.3 & 1.8 & 2 \\
\hline $\mathbf{3}$ & 3 & 3 & 3 & 2.6 & 3 & 2 \\
\hline $\mathbf{4}$ & 3.6 & 4 & 3.7 & 4 & 3.7 & 3 \\
\hline $\mathbf{5}$ & 5 & 5.3 & 4.5 & 5 & 4.8 & 4 \\
\hline $\mathbf{6}$ & 5.2 & 6 & 5.5 & 5.5 & 5.8 & 5 \\
\hline $\mathbf{7}$ & 7 & 6.5 & 6.3 & 6.3 & 6 & 6 \\
\hline $\mathbf{8}$ & 7.5 & 7.8 & 7.3 & 7 & 8 & 7 \\
\hline $\mathbf{9}$ & 8.7 & 8 & 8 & 8.7 & 8.2 & 8 \\
\hline $\mathbf{1 0}$ & 9.5 & 9.2 & 8.8 & 9.8 & 9 & 9 \\
\hline
\end{tabular}

KESIMPULAN

Kesimpulan yang dapat diambil dari perancangan alat pencetak tanggal kadaluarsa pada plastik pack dengan metode

hot stamping adalah :

a. Alat pencetak tanggal kadaluarsa pada kemasan plastik ini dapat mencetak tanggal kadaluarsa pada plastik dengan jarak stamping head $2,6 \mathrm{~cm}$.

b. Jarak pencetakan dideterminasikan dengan input mode dari pengguna yang dibantu oleh sensor eye-mark sesuai dengan layout design plastik. Mulai dari jarak rata-rata 1,22 cm untuk Mode 1, hingga 9,26 cm untuk Mode 10. 


\section{DAFTAR PUSTAKA}

[1] SNI $02-2724-2002,18$ Mei 2015 pukul 21.00, $\underline{\text { http://sisni.bsn.go.id/in }}$ dex.php?/sni_main/sni/detail_sni/6634.

[2] Elite Snacks and salade, 10 Juni 2015 pukul 08.40, http://www.linx global.com/en$\mathrm{gb} / \mathrm{about} / \mathrm{case}$-studies/elite- snacks.

[3] Amstead. B.H, Teknologi Mekanik. Jakarta: Erlangga, 1995, hal. 228.

[4] Reed. R. P., Measurement Instrumentation Sensors, USA: CRC Press LLC, 1999, pp. 1019.

[5] Hughes J. M., Practical Electronics Components and Techniques, USA: O'Reilly Media, Inc, 2015, pp 139-399.

[6] Coles. Richard dan Kirwan. Mark, Food and Beverage Packaging Technology. UK:WileyBlackwell, 2011, pp 204. 